\title{
Author Index (Volume 3)
}

\begin{tabular}{|c|c|c|}
\hline Abbas, I. A. $\quad 1550003,1550004$ & Kamble, V. G. 1550005 & Panda, H. S. 1550005 \\
\hline Al Dabbas, H. A. 1550005 & Khoo, R. S. H. 1540007 & \\
\hline Al-Sayed, A. 1550001 & Kumar, R. 1550003,1550004 & 1540008 \\
\hline An, T. 1540006 & Kumar, S. 1540008 & Salem, Al. M. 1550001 \\
\hline Braunstein, P. 1540007 & $\begin{array}{l}\text { Lahiri, A. } 1550003 \\
\text { Lai, Z. } 1540001\end{array}$ & $\begin{array}{l}\text { Soh, C. B. } 1550002 \\
\text { Sumboja, A. } 1540006\end{array}$ \\
\hline Chen, W. 1540001 & Li, B. 1540006 & \\
\hline Chi, D. Z. 1550002 & Li, C. G. 1550002 & Tam, T. L. D. \\
\hline Chua, S. J. 1550002 & $\begin{array}{ll}\mathrm{Li}, \mathrm{H} . & 1540001 \\
\mathrm{Li}, \mathrm{X} . & 1540005\end{array}$ & Weng, Z. 1540001 \\
\hline Das, S. 1540008 & Liu, H. F. 1550002 & $\begin{array}{l}\text { Wong, S. Y. } 1540005 \\
\text { Wu, J. } 1540003\end{array}$ \\
\hline Fan, Z. 1540001 & $\begin{array}{l}\text { Liu, W. } 1550002 \\
\text { Liu. X } \quad 1540001.1540002\end{array}$ & Wu, X. 1540004 \\
\hline Fernandez, J. B. 1550005 & Liu, Z. 1540006 & Wuu, D. 1540006 \\
\hline Ge, X. 1540006 & $\begin{array}{ll}\text { Lotfy, Kh. } & 1550001 \\
\text { Luo, H.-K. } & 1540007\end{array}$ & $\begin{array}{ll}\text { Yap, R. C. C. } & 1540005 \\
\text { Young, D. J. } & 1540004\end{array}$ \\
\hline $\begin{array}{l}\text { Han, Y. } 1540002 \\
\text { He, J. } 1540005 \\
\text { Hor, T. S. A. } 1540004, \\
\text { 1540006, } 1540007 \\
\text { Huano J } 1550002\end{array}$ & $\begin{array}{lc}\text { Mallick, A. } & 1540008 \\
\text { Marin, M. } & 1550004 \\
\text { Meng, C. } & 1540002 \\
\text { Mishra, P. } & 1550005\end{array}$ & $\begin{array}{l}\text { Zheng, B. } 1540001 \\
\text { Zong, Y. } \quad 1540006\end{array}$ \\
\hline
\end{tabular}

